\title{
EXPERIMENTAL PROBLEM OF INDIRECTLY DETECTING ENGINE TORQUE DELIVERED BY AGRICULTURAL MACHINES THROUGH EXHAUST GAS TEMPERATURE
}

\author{
Marco Bietresato, Francesco Selmo, Massimiliano Renzi, Fabrizio Mazzetto \\ Libera Universita di Bolzano, Italy \\ marco.bietresato@unibz.it
}

\begin{abstract}
Measuring the performance of the compression-ignition internal combustion engine of agricultural machines (in particular, the torque delivered instantaneously) is an essential requirement for monitoring: (a) the exploitation of the engine mechanical-energy potential (in terms of generated torque) and (b) its correct operation (in terms of global efficiency, fuel consumption and possible ageing). Due to the many important technical and economic implications, the instant acquisition of the engine torque is therefore a critical point in any operational monitoring system, as well as in predictive maintenance models. Torque measurement is by no means a simple task, especially in old agricultural machines lacking of default data acquisition devices/on-board electronics, and many critical issues arise from the fact that it involves rotating components (shafts), which are often difficult to be accessed. For this reason, an indirect torque measurement methodology, based on a predictive model relying on the exhaust gas temperature, is preferable. An accurate measurement of temperature data is of primary importance to precisely calculate the torque, which means performing an accurate thermocouple choice, placement, and data elaboration. This is made even more challenging by the fact that the temperature of the exhaust gas is often in a transient state due to variable engine regime necessary for machine operation. The study presented here illustrates some considerations about the trend and the equation of the experimental measurements of the exhaust gas temperature, considering three different positions for the thermocouples on the exhaust line, and proposes an optimal technical solution in terms of sensitivity and promptness of response.
\end{abstract}

Keywords: farm machinery, diesel engines, engine performance, fuel gas temperature, temperature sensor position, Newton's equation.

\section{Introduction}

Nowadays agricultural machines give a fundamental and unavoidable support to human work, both in developed and in developing countries, and the production of a sufficient amount of food (at economically- and environmentally-sustainable conditions) is unthinkable without the utilization of these machines $[1 ; 2]$ Unfortunately, a large amount of these vehicles is very old, especially (but not only) in developing countries, due to a generalised low replacement rate. Just to give some examples, more than one half of the circulating agricultural machines in Italy (estimated to be about 2100000 units) are more than 20 years old, and around 30\% of the total circulating machines are more than 33 years old [3;4]. The use of these out-of-date vehicles may cause many problems related to safety, pollutant emissions, reliability, performance decay and maintenance (that are also linked to decreases in productivity). However, what makes things even more complicated on old machines, is the absence of sensors or other modern apparatuses able to give the users some information about the previously listed issues. Having reliable data would allow to implement some optimization strategies, to reduce possible problems, ruptures and so on, thus bringing to effective benefits. This is the reason why a data acquisition system placed on these machines would be of great importance [5]. In this context, the exhaust gas temperature (EGT) is one of the most meaningful parameters that can be monitored, as it can provide information about the torque, combustion quality, pollutants [6-9]. The correlation between the EGT and the torque is proven [10-13] with the most approximated equation that gives a linear correlation between these two quantities. However, more elaborate models can give a dependence also from the rotational regime [14]. In each case, many studies often correlate EGT and torque during stationary operating conditions for the engine (i.e., at constant values of engine rotational speed or torque), but very little information could be found on what happens during operative transients between one engine regime to another one, or with different levels of torque to be delivered. It is worth noting that the torque applied by a vehicle engine during its working day can change many times, depending on the tasks to be performed, so the EGT measured at the exhaust is often in a transient status caused by even-sudden load changes. Due to the presence of many materials involved in the transmission of heat from the exhaust gas to a possible temperature probe, the measured temperature can be temporarily misaligned with the effective EGT. This means that a possible change in the measured temperature does not follow instantaneously a change of the applied torque; even in stationary conditions 
for the engine (i.e., with the average EGT value constant), the temperature measured by a probe varies over time and asymptotically tends to a stationary value only when all the other conditions are kept constant for enough time. This time dependence is due to many factors, some related to the physical components of the duct and the engine, and some others directly connected to the gas stream. The factors related to the duct and the engine are the thermal-physical properties of the solid materials, the length of the path travelled by the exhaust gas from the combustion chamber to the measurement location, the shape of all the components, and the possible presence of heat dissipation devices. Instead, the time dependence due to the gas stream can be also affected by the local speed of the exhaust gases in correspondence to the measuring point, and, more in general, by all the fluid-dynamic characteristics of the gas flow $[7 ; 13 ; 15-18]$. The transient response also depends on the position and the type of the measuring instrument employed [19]. For example, a thermocouple (from now on: "TC") can be placed in more or less direct contact with the gas flux, e.g., inside the exhaust pipe (with a thermowell), or in contact with the external surface of the duct or other thermally-conductive bodies, thus leading to very different results in terms of the absolute value of the temperature and promptness of the measure after stabilization of the torque to a new value. Therefore, the effect of the above-mentioned aspects on the transient response has to be analysed to determine the values of all the parameters of the equation driving the temperature changes and, possibly, use these mathematical models to determine the asymptotic temperature even without reaching it.

In this preliminary work, the combined effect of all the variables on temperature transients will be considered. The aim of this study is to compare three different positions for installing a thermocouple along the exhaust line. The comparisons will be done after fitting the experimental data with the Newton's equation and, hence, will involve the parameters of this equation. These parameters will be used to establish the better position of placing the thermocouples, in terms of promptness of response i.e., time response, when a load variation is applied to the engine, thus generating a variation of the EGT, and resolution, i.e., sensitivity to torque variations.

\section{Materials and methods}

The experimental setup used to perform this study is essentially composed by three parts (Fig. 1): (i) an internal combustion engine, (ii) a dynamometric brake, and (iii) a data-collection system with some sensors connected to it [13]. The engine is a single-cylinder 4-stroke diesel engine (model "15LD225" by Lombardini S.r.l., Reggio Emilia, Italy [20]; see Table 1), equipped with an ad-hoc designed exhaust pipe. The engine is connected via a shaft to the dyno brake (model "Braker-Engine 100/E" by Soft-Engine S.r.l., Falconara Marittima, Ancona, Italy [21]), which is provided with a software interface that gives the possibility to manually set the rotational speed and the torque applied to the engine. The sensors used for this study (see Table 2 for specifications), all connected to a "cDAQ 9178" data logger (by National Instruments, Austin, TX, USA [22]), are essentially divided into two groups: (1) an encoder and a load cell, already equipping the dyno brake, used to acquire the rotational speed and the torque that the engine is instantaneously exerting; (2) three K-type TCs (positioned along the engine exhaust duct, as represented in Fig. 2).

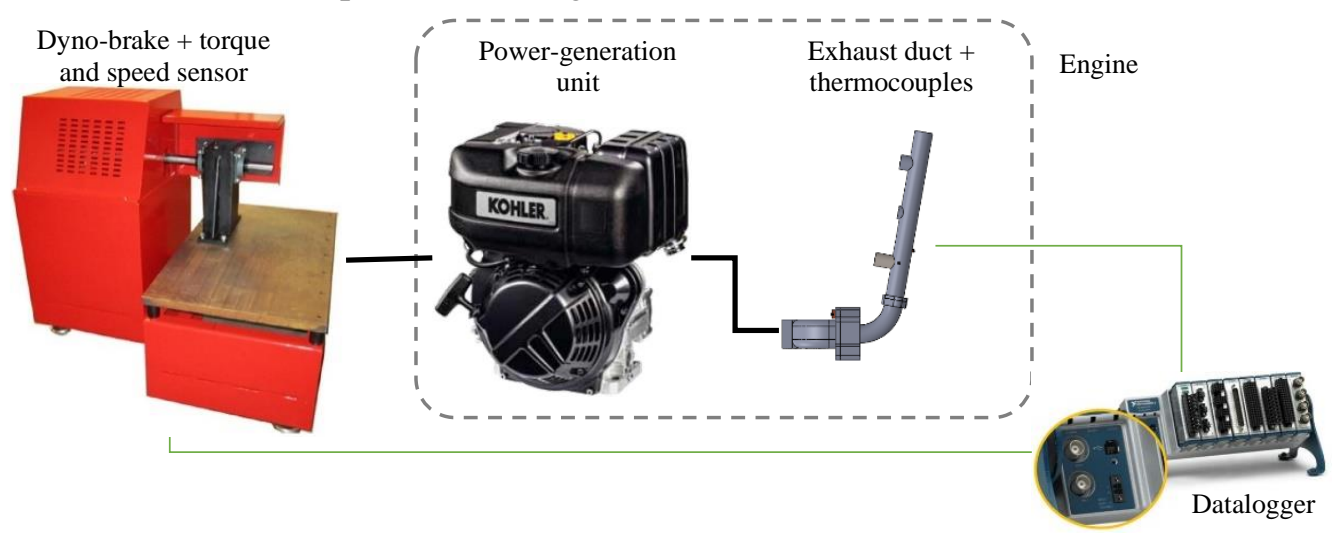

Fig. 1. Scheme of the experimental setup: black lines are the physical (mechanical) connections; green lines represent the electric wiring for the sensors 
Lombardini 15LD225 engine specifications

\begin{tabular}{|c|c|}
\hline Description & Specification \\
\hline $\begin{array}{l}\text { Cylinders (number; configuration; } \\
\text { total displacement; bore } \times \text { stroke) }\end{array}$ & 1; vertical; $224 \mathrm{~cm}^{3} ; 69 \mathrm{~mm} \times 60 \mathrm{~mm}$ \\
\hline Fuel-system type & With: direct injection, mechanical speed regulator \\
\hline Cooling type & Using forced-air circulation moved by the bladed flywheel \\
\hline Nominal power (value; engine speed) & 3.5 kW @ 3600 rpm (80/1269/CEE - ISO 1585:2020) \\
\hline $\begin{array}{l}\text { Maximum torque (value; engine } \\
\text { speed) }\end{array}$ & 10.4 Nm@2400 rpm \\
\hline Maximum speed & $3600 \mathrm{rpm}$ \\
\hline
\end{tabular}

Sensor and datalogger specifications

\begin{tabular}{|l|l|l|}
\hline Sensor/Component & \multicolumn{1}{|c|}{ Manufacturer, Model } & \multicolumn{1}{c|}{ Specification } \\
\hline Thermocouples & N/A, K type & $\begin{array}{l}\text { Operating temperature up to } 800{ }^{\circ} \mathrm{C} \\
(1073 \mathrm{~K})\end{array}$ \\
\hline $\begin{array}{l}\text { Rotational speed } \\
\text { meter (of the dyno) }\end{array}$ & $\begin{array}{l}\text { Telestar, Minicod-T 1000 } \\
5 / 24 \mathrm{~B} 1000\end{array}$ & $\begin{array}{l}\text { Input voltage 5-30 V, Sampling speed } \\
100 \mathrm{kHz}, \text { max rotation speed 6000 rpm }\end{array}$ \\
\hline $\begin{array}{l}\text { Torque meter (of } \\
\text { the dyno) }\end{array}$ & $\begin{array}{l}\text { Laumas Elettronica, CTL } \\
500\end{array}$ & $\begin{array}{l}\text { Max load 500 kgf, max supply voltage 15 V, } \\
\text { rated output 2 mV/V } \pm 0.1 \%,\end{array}$ \\
\hline Datalogger & $\begin{array}{l}\text { National Instruments, C-Daq } \\
9178\end{array}$ & $\begin{array}{l}\text { Input voltage 9-30 V, power 15 W, max } \\
\text { frequency } 1 \mathrm{MHz}\end{array}$ \\
\hline
\end{tabular}

A detailed view of the TCs location is given in Fig. 2. They have three different positions along the exhaust duct and three different fixing solutions. The position is determined by measuring the distance along the axis of the exhaust gas ducts between each TC and a reference plane (indicated in the same Fig.), with the positive direction directed towards the outlet. The reference plane is set at the joining section between the engine head and the stainless-steel exhaust duct. The next list gives the specifications for each TC.

- The first TC ("TC1") has its final part shaped as a grommet, thus allowing to fix it on the bolt holding the exhaust duct on the engine case. It is placed at $-7 \mathrm{~mm}$ from the reference plane.

- The second TC ("TC2") has its tip in contact with the external surface of the straight part of the exhaust duct, immediately after the thermowell seating the third thermocouple. It is held in position by a clamp wrapping the pipe. It is placed at $+190 \mathrm{~mm}$ from the reference plane.

- The third TC ("TC3") has its tip inserted into a thermowell screwed in a specific seat of the exhaust pipe. The thermowell arrives at a depth that is approximately at the pipe axis and its external walls are in direct contact with the exhaust gases. The tip of the thermocouple is in touch with the bottom of the thermowell. Its position is at $+170 \mathrm{~mm}$ from the reference plane.

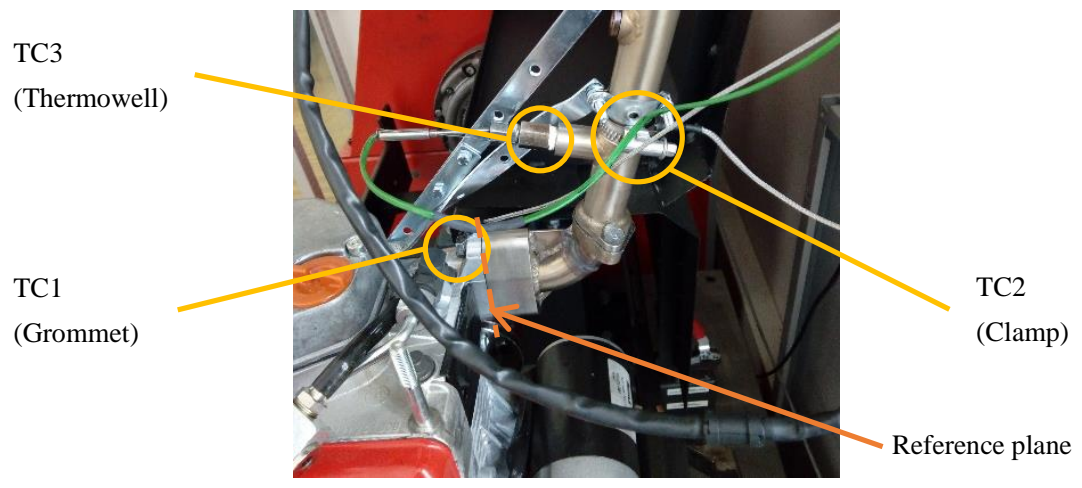

Fig. 2. Positioning of the three thermocouples along the exhaust system

The experimental test was performed as described hereinafter; in particular four phases can be individuated: 
1. the torque $M$ was set initially at the nominal value of $8.00 \mathrm{Nm}(8.15 \mathrm{Nm}$ on average after precise measurement) for a time sufficient to let the three TCs reach a constant value for the measured temperature;

2. after stationary thermal conditions were reached for the three TCs, the torque applied to the engine was set to zero for 60 seconds.

3. then, the torque $M$ was suddenly brought again to the nominal value of $8.00 \mathrm{Nm}(8.09 \mathrm{Nm}$ on average after measurement) and kept constant for a time sufficient to reach again stationary conditions for the TCs measurements (about $500 \mathrm{~s}$ );

4. the torque was finally set to $0 \mathrm{Nm}$ again and the temperature recording was stopped.

The whole experiment lasted about $1400 \mathrm{~s}$, and the data sampling frequency was set to $0.1 \mathrm{~Hz}$. Temperature data were recorded by the three TCs at the same time and then they were analysed using a spreadsheet (i.e., Microsoft Excel). Due to the physical conditions of the fluid (here: a hot gas flowing within a pipe), causing the heating of the solid material in contact with each of the TCs, the values of the Biot number (Bi) are lower than 0.042 for TC2 and TC3 (and at the most equal to 0.106 for TC1), hence these values indicate that the limiting factor for the heat transmission mechanism is, in this case, the convection from the gas to the solid components [23-25]. Also, as it is possible to hypothesize a constant value for the average flow rate of the exhaust gas (hence a pseudo steady-state condition for the forcing heat source), the transient condition of the solid materials in contact with the exhaust gas (i.e., the dependence of the measured temperature $T$ in ${ }^{\circ} \mathrm{C}$ as a function of the time $t$, measured in $\mathrm{s}$ ) can be expressed by using the Newton's equation for a heating (or cooling) body [26,27], expressed in the following form (see also Fig. 3):

$$
T(t)=A-B \cdot e^{-\frac{t-t_{0}}{\tau}},
$$

where $A$ - parameter representing the temperature value that a TC would measure after a sufficiently long period of time (when all the components of the measuring system would be in equilibrium with the exhaust gas in contact with them); geometrically speaking, it locates vertically the horizontal asymptote, measured in ${ }^{\circ} \mathrm{C}$;

$B$ - parameter representing the difference between the initial and the final value for the temperature measured by a TC, measured in ${ }^{\circ} \mathrm{C}$;

$\tau$-so-called "time constant" of the whole system (here: the combination of the solid walls in contact with the exhaust gas, and of the TC in contact with these walls); geometrically speaking, it is the horizontal distance between the initial point and the intercept of the tangent line at the initial point and the horizontal asymptote at $A$; technically speaking, for such an exponential system it is possible to consider that the temperature measurement has reached a constant value (represented by parameter $A$ ) after a time corresponding to three times the time constant, measured in seconds; $t_{0}$ - initial time instant of the considered heat-transfer phenomenon, measured in seconds.

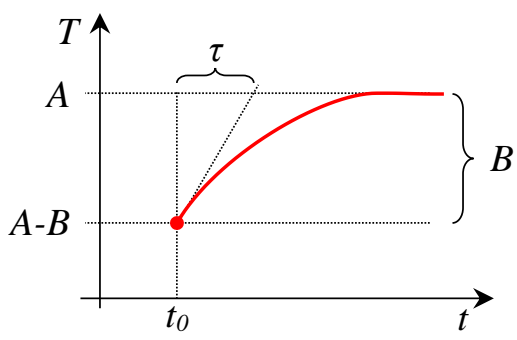

Fig. 3. Geometrical interpretation of the three parameters $(A, B, \tau)$ influencing the shape of the exponential curve representing the Newton's equation

The least squares method was used to find the best fit for the experimental data with the abovereported exponential curve, which means finding the values of the three constants $A, B, \tau$ of equation (1) that best approximate the data in the collected series. In order to assess the quality of the fitting operation and overcome the numerical limitations of Microsoft Excel, the coefficient of determination $R^{2}$ has been calculated using the following formula [28] with the data collected by each of the three TCs: 


$$
R^{2}=1-\frac{\sum_{i}\left(y_{i}-y_{c, i}\right)^{2}}{\sum_{i}\left(y_{i}-\bar{y}\right)^{2}},
$$

where $y_{i}$-experimental datum for the temperature measured by the considered TC at the time instant $t_{i}$

$y_{c, i}-$ temperature value calculated with the best fit coefficients for Eq. 1 in correspondence with the time instant $t_{i}$;

$\bar{y}$ - average of all the experimental data for the considered TC.

\section{Results and discussion}

The data series acquired during the experimentation can be seen in the Cartesian graph of Fig. 4, having in abscissa the time elapsed from the start of the experiment. The values of temperature detected by the three TCs are reported on the left axis, whereas the torque values (represented by the blue dots in the plane) are reported on the right. In the first phase (named I) temperature at the three locations reached stationary conditions. The phase II is the one at which the torque was temporary set to zero. Temperature decreases with a different rate for the three TCs. Phase III' is a "joining" section, in which, after the torque is suddenly increased again to the nominal value of $8 \mathrm{Nm}$, temperature stops dropping and then starts to raise again (curve concavity is directed upward). Note that there is a well-visible lag between the moment at which the engine torque really increases and the moment at which the temperature, measured at the three previously indicated locations, starts rising again till reaching a constant value, typical of the level of torque effectively being delivered by the engine. Section III of the curves includes the data used for fitting the Newton's exponential curve. Finally, phase IV is characterized by cooling of the system after the engine torque was set again to zero.

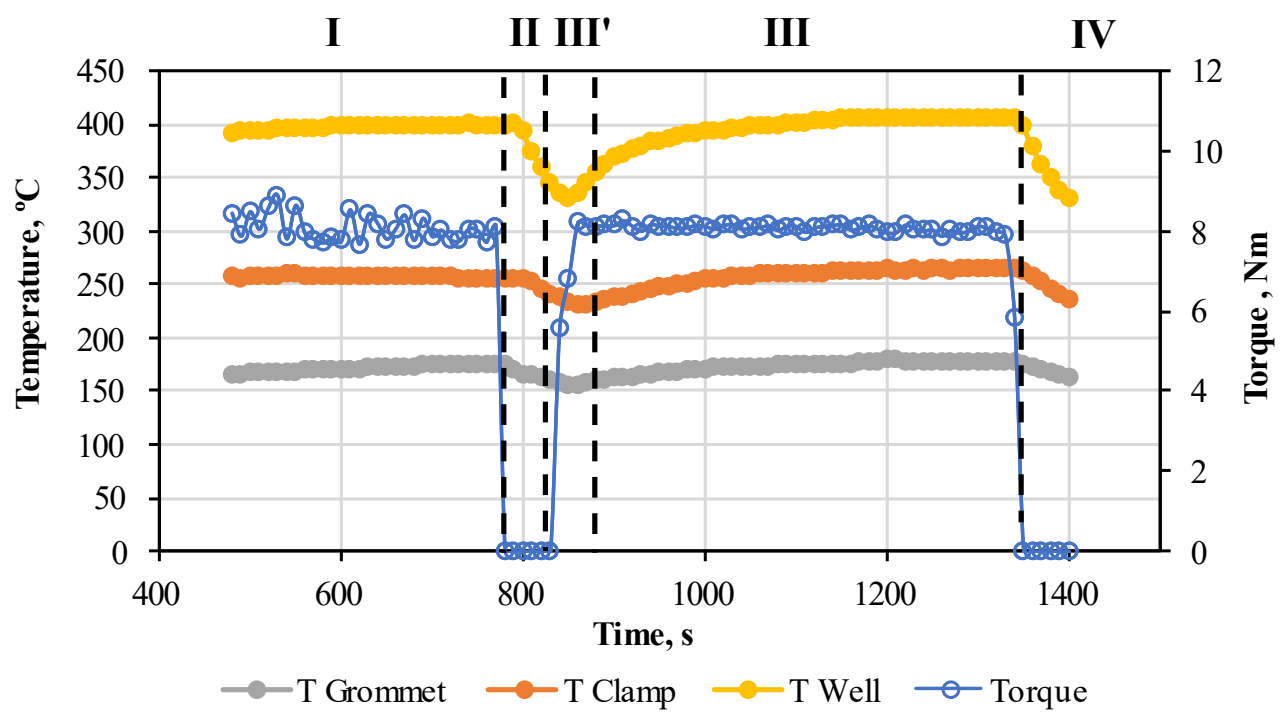

Fig. 4. Experimental temperature data from the thermocouples at the three indicated locations (left vertical axis) and torque (right vertical axis) as a function of the elapsed time

(I, II, III, IV: different phases individuated in the development of the experiment; see text)

To give an example, Fig. 5 shows graphically the result of the fitting operation of the experimental data (yellow points) with the curve obtained using the Newton's exponential equation (black curve) for the thermocouple placed inside the thermowell. The $R^{2}$ parameter value in this case is 0.992 , which means that there is a very good fitting. Fig. 6 shows three charts comparing the experimental results with the values calculated using the exponential formula. In all these cases, the points lie almost perfectly on the diagonal $\left(R^{2} \geq 0.981\right.$, calculated in all the three cases with respect to the bisector line of the first quadrant), thus confirming the good quality of the fitting operation. 


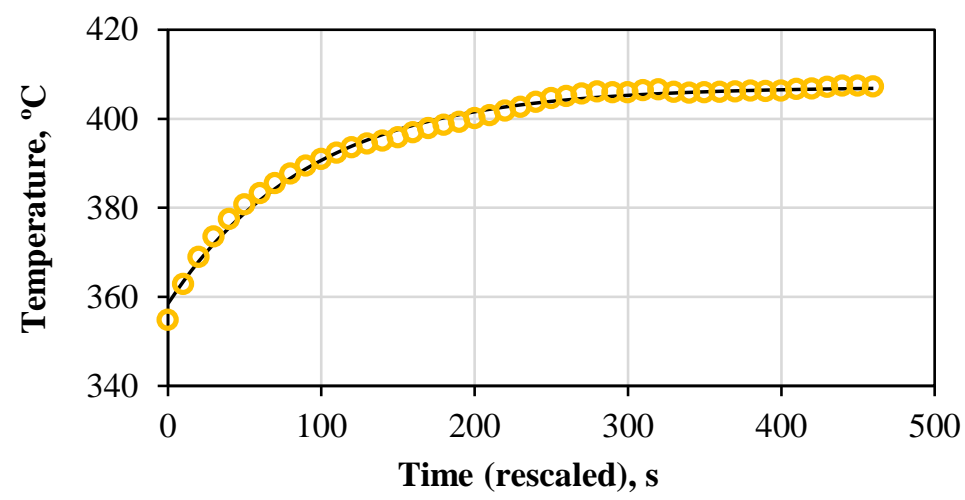

Fig. 5. TC3 experimental data fitted with an exponential curve $\left(A=407.16^{\circ} \mathrm{C} ; B=48.69^{\circ} \mathrm{C} ; \tau=92.38 \mathrm{~s}\right)$.

a)

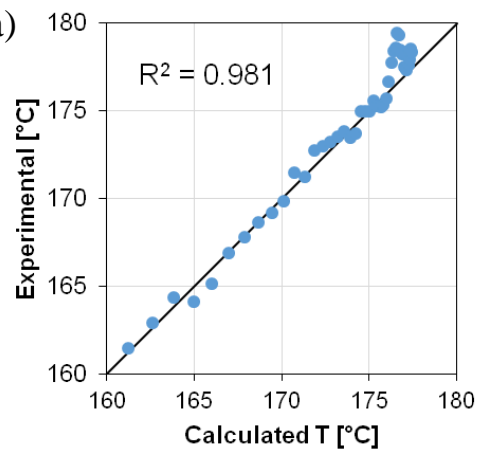

b)

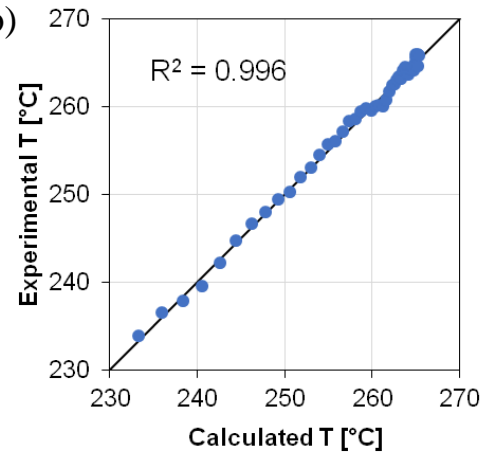

c)

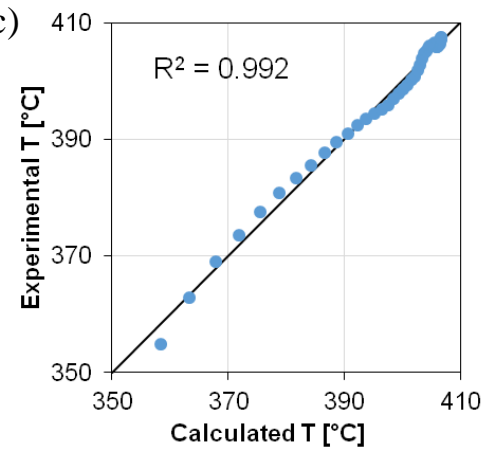

Fig. 6. Comparison between experimental and calculated temperature data for the three locations for the thermocouples: $\mathrm{a}$ - grommet $\mathrm{TC} 1 ; \mathrm{b}$ - clamp TC2; $\mathrm{c}$-thermowell TC3

Table 3 summarizes the results for all the three data series. Firstly, by observing the high $R^{2}$ values obtained (all greater than 0.981 , corresponding to the grommet TC1), it is possible to note that the fitting with the Newton's equation was very accurate for all the three positions of the thermocouples. This means that it is possible to refer to the parameters of that equation $(A, B, \tau)$ to make proper comparisons amongst the three TCs responses and, hence, amongst the three inquired locations to install a TC to monitor the engine torque output. As expectable, the parameter $A$, which is related to the position of each thermocouple along the exhaust line (and to its more or less direct exposition to the thermal source), varies greatly with the considered thermocouple/position. Specifically, $A$ is greater for the TC placed in the thermowell $\left(407.16^{\circ} \mathrm{C}\right)$, lower for the TC1 integrated in the grommet $\left(177.77^{\circ} \mathrm{C}\right)$. It can be noted that also the parameter $B$, which represents the total excursion of temperature between the beginning and the final (constant) part of each curve, varies with the position of the considered TC. Indeed, the grommet TC has the lowest value of $B\left(18.01{ }^{\circ} \mathrm{C}\right)$, whereas the thermowell TC3 has the highest value $\left(48.69^{\circ} \mathrm{C}\right.$ ), thus indicating a higher thermal excursion to a torque increment $\Delta M$ from 0 to $8.09 \mathrm{Nm}$, hence a higher resolution (in terms of rise in measured temperature per unit of torque). However, in the investigated cases, the ratio between $B$ and $A$ is almost constant with an average value of 11.46, suggesting a proportionality between the heat load and the reached maximum temperature, as expectable, thanks to the contemporaneity between the measurements with the three TCs and the unicity of the thermal source. The value of the time constant $\tau$ changes in general depending on the considered thermocouple (hence with the placement on the exhaust line); the TC that has the fastest response to torque changes is the thermowell thermocouple, having a time constant equal to $92.38 \mathrm{~s}$. The other two TCs have very similar values of $\tau$ (116.65 s for the TC1 grommet, $119.77 \mathrm{~s}$ for the TC 2 clamp) and the difference between their time constants is about $3 \%$. The higher promptness of response is also visible looking at the ratio $B / \tau$, which is related to the speed of increasing of the temperature measured by a TC. Also in this case, the TC3 thermowell has the highest value $\left(0.53{ }^{\circ} \mathrm{C} \cdot \mathrm{s}^{-1}\right.$, i.e., $+241 \%$ higher than TC1 grommet). Notwithstanding this, TC has $B$ greater by $170 \%$ with respect to the value of TC1 grommet, it is however the quickest to reach the constant temperature due to a non-proportionality between the 
increment of $B$ and the increment of $B / \tau(+241 \%)$, meaning that the TC3 thermowell has a net advantage in detecting quickly the exhaust gas temperature associated with an imposed level of the torque delivered by the engine (indeed, the $\tau$ is $21 \%$ smaller than the $\tau$ of the TC1 grommet). The same comment cannot be said for the TC2 clamp, as it has an increment of the $B / \tau$ ratio $(+77 \%)$ that is not so high as the increment scored for the parameter $B(+82 \%)$, resulting in a slight increment of the time constant $\tau$ $(+3 \%)$ with respect to $\mathrm{TC} 1$ grommet.

Table 3

Results from elaboration of temperature data series for a torque of $8.09 \mathrm{Nm}$

\begin{tabular}{|c|c|c|c|c|c|c|c|c|}
\hline \multicolumn{2}{|c|}{ Quantity } & Unit & TC1 (g & nmet) & TC2 & amp) & TC3 (t) & rmowell) \\
\hline \multirow{4}{*}{$\begin{array}{l}\text { Newton's } \\
\text { equation } \\
\text { fitting }\end{array}$} & $A$ & ${ }^{\circ} \mathrm{C}$ & 177.77 & (ref.) & 266.06 & $(+50 \%)$ & 407.16 & $(+129 \%)$ \\
\hline & $B$ & ${ }^{\circ} \mathrm{C}$ & 18.01 & (ref.) & 32.70 & $(+82 \%)$ & 48.69 & $(+170 \%)$ \\
\hline & $\bar{\tau}$ & $\mathrm{s}$ & 116.65 & (ref.) & 119.77 & $(+3 \%)$ & 92.38 & $(-21 \%)$ \\
\hline & $R^{2}$ & - & \multicolumn{2}{|c|}{0.981} & \multicolumn{2}{|c|}{0.996} & \multicolumn{2}{|c|}{0.992} \\
\hline \multirow{3}{*}{$\begin{array}{c}\text { Derived } \\
\text { quantities }\end{array}$} & $B / A$ & - & 0.101 & (ref.) & 0.123 & $(+21 \%)$ & 0.120 & $(+18 \%)$ \\
\hline & $B / \tau$ & ${ }^{\circ} \mathrm{C} \cdot \mathrm{s}^{-1}$ & 0.154 & (ref.) & 0.273 & $(+77 \%)$ & 0.527 & $(+241 \%)$ \\
\hline & $B / \Delta M$ & ${ }^{\circ} \mathrm{C} \cdot(\mathrm{Nm})^{-1}$ & 2.226 & (ref.) & 4.042 & $(+82 \%)$ & 6.019 & $(+170 \%)$ \\
\hline
\end{tabular}

\section{Conclusions}

The positioning of a temperature probe along the exhaust line in order to detect indirectly the torque delivered by an engine must be done very carefully. Indeed, the position chosen could seriously affect the readings, especially because of the different response speed that this temperature probe will have. According to the experiments carried out, after fitting the data with the Newton's equation, it was possible to observe that a thermocouple inserted through a thermowell inside the exhaust line has a response time (in terms of time constant $\tau$ ) $21 \%$ lower than a thermocouple connected to the exhaust line through a grommet, marking the absolute best value for this parameter $(116.65 \mathrm{~s})$. The same thermocouple has also a higher resolution to torque variations, $6.019^{\circ} \mathrm{C} \cdot(\mathrm{Nm})^{-1}$, i.e., $170 \%$ higher than the grommet TC1, again taken as reference. For all the previously illustrated reasons, it is highly recommendable to install a thermocouple in a thermowell. The next steps foresee the execution of similar trials but at different levels of the engine torque, to obtain other values for the Newton's equation parameters $(A, B, \tau)$ and possibly relate them to the torque $M$ with continuous equations $A(M), B(M)$, $\tau(M)$. Thanks to these equations (and their inverse functions), it will be possible to relate the engine torque to the temperature trends even without waiting for them to reach a constant value.

\section{References}

[1] FAO. AGRICULTURE 4.0 Start Agricultural robotics and automated equipment for sustainable crop production. vol. 24. Food and Agriculture Organization of the United Nations; 2020.

[2] Sims B., Hilmi M., Kienzle J. Agricultural mechanization A key input for sub-Saharan African smallholders. vol. 23. 2016.

[3] Pala S.G. Macchine agricole: la sicurezza non è un optional. AgroNotizie 2019. https://agronotizie.imagelinenetwork.com/agrimeccanica/2019/02/14/macchine-agricole-lasicurezza-non-e-un-optional/61760.

[4] Audizione in Senato per FederUnacoma - FederUnacoma n.d.

[5] Mazzetto F., Bietresato M. Proposal of a local telemetry network for the monitoring the thermodynamic and environmental performances of farm tractors. J Agric Eng 2013; 44. DOI: 10.4081/jae.2013.(s1):e25.

[6] Wu G., Ge J.C., Choi N.J. A Comprehensive Review of the Application Characteristics of Biodiesel Blends in Diesel Engines. Appl Sci 2020;10:8015. DOI: 10.3390/app10228015.

[7] Kapparos D.J., Foster D.E., Rutland C.J. Sensitivity Analysis of a Diesel Exhaust System Thermal Model. SAE Tech. Pap., 2004. DOI: 10.4271/2004-01-1131.

[8] Alkidas A.C., Battiston P.A., Kapparos D.J. Thermal Studies in the Exhaust System of a DieselPowered Light-Duty Vehicle. SAE Tech. Pap., vol. 113, 2004, pp. 164-181. DOI: 10.4271/200401-0050. 
[9] Fortunato F., Caprio M., Oliva P., D’Aniello G., Pantaleone P., Andreozzi A. et al. Numerical and Experimental Investigation of the Thermal Behavior of a Complete Exhaust System. SAE Tech. Pap., vol. 2007, 2007. DOI: 10.4271/2007-01-1094.

[10] Bietresato M., Calcante A., Mazzetto F. A neural network approach for indirectly estimating farm tractors engine performances. Fuel 2015;143, pp. 144-154. DOI: 10.1016/j.fuel.2014.11.019.

[11] Bietresato M., Malavasi M., Mazzetto F. An Approach to the Development of an Integrated RealTime Engine Test System for Agricultural Machines: Conceiving, Implementation, Set-up and First Tests. In: A. Coppola et al., editor. Innov. Biosyst. Eng. Sustain. Agric. For. Food Prod., Springer Nature Switzerland AG; 2020, pp. 551-562. DOI: 10.1007/978-3-030-39299-4_61.

[12] Bietresato M., Malavasi M., Mazzetto F. Set-up of integrated system for real-time detection and recording of many engine parameters of agricultural machines during Dyno tests. Eng. Rural Dev., vol. 18, 2019. DOI: 10.22616/ERDev2019.18.N187.

[13] Bietresato M, Selmo F, Renzi M, Mazzetto F. Torque Prediction Model of a CI Engine for Agricultural Purposes Based on Exhaust Gas Temperatures and CFD-FVM Methodologies Validated with Experimental Tests. Appl Sci 2021;11: 3892. DOI: 10.3390/app11093892.

[14] De Souza E.G., Milanez L.F. Indirect evaluation of the torque of diesel engines. Trans ASAE 1988;31, pp. 1350-1354.

[15]Zhang X., Romzek M. Computational Fluid Dynamics (CFD) Applications in Vehicle Exhaust System. SAE Tech. Pap., vol. 2008, 2008, pp. 776-790. DOI: 10.4271/2008-01-0612.

[16] Bannister C.D., Brace C.J., Taylor J., Brooks T., Fraser N. The use of multi-variate models for the prediction of heat transfer in vehicle exhaust systems. Proc Inst Mech Eng Part D J Automob Eng 2010;224, pp. 369-385. DOI: 10.1243/09544070JAUTO1283.

[17] Fernández-Yáñez P., Armas O., Gómez A., Gil A. Developing Computational Fluid Dynamics (CFD) Models to Evaluate Available Energy in Exhaust Systems of Diesel Light-Duty Vehicles. Appl Sci 2017;7, 590p. DOI: 10.3390/app7060590.

[18] Rony R.U., Hasan N., Ashiqur M., Laskar R. Heat Transfer of Pulsating Turbulent Flow in Pipes. Eur J Adv Eng Technol 2018;5, 511-516. DOI: 10.6084/M9.FIGSHARE.12520691.V1.

[19] Cavina N. Measurement of Exhaust Gas Temperatures: Theoretical and Experimental Analysis. ASME ICE 2002 Fall Tech. Conf., New Orleans, Louisiana, USA: 2002, p. 1-9.

[20] Kohler Power | Kohler Engines n.d.

[21] Soft-Engine | Home n.d.

[22] Bietresato M., Renzi M., Mischiatti S., Mazzetto F. Engine test stand layout and post processing tools for the detection of many engine performance parameters. ARPN J Eng Appl Sci 2016;11.

[23] Pompei C. Operazioni Unitarie della tecnologia alimentare. Milano: Milano: Casa editrice ambrosiana; 2009.

[24] Incropera F.P., DeWitt D.P. Fundamentals of Heat and Mass Transfer. Hoboken, NJ, USA: John Wiley \&amp; Sons, Inc.; 1996.

[25] Friso D. Ingegneria dell'industria agroalimentare - Volume I - Teoria, Applicazioni e Dimensionamento delle Macchine e Impianti per le Operazioni Unitarie. CLEUP; 2017.

[26] VII. Scala graduum caloris. Philos Trans R Soc London 1701;22, pp. 824-829. DOI: $10.1098 /$ rstl.1700.0082.

[27] Struthers A., Potter M. Differential Equations. Cham: Springer International Publishing; 2019. DOI: 10.1007/978-3-030-20506-5.

[28] Montgomery D.C. Design and Analysis of Experiments. vol. 2. 2013. DOI: $10.1198 /$ tech.2006.s372. 